\title{
Ayurvedic Treatment for Osteoarthritis
}

\section{Osteoarthritis}

Osteoarthritis is one of the most prevalent and chronic diseases of today's world. Despite various research work and studies have been done in this regard still an effective cure is not available. Ayurveda offers effective, long-lasting and safe remedies for this chronic disease.

\section{Causes of Osteoarthritis}

Vitiation of Vata Dosha is a cause of Osteoarthritis, Consumption of dry, cold or stale food, irregular sleeping habits, suppression of natural urges, and exposure to severe cold, and dry weather. Due to aging, excessive strain on the joint, any injury to the joint, are the frequent causes of arthritis.

\section{Symptoms of Osteoarthritis}

Moderate to severe pain in joints. Stiffness in affected joints especially after resting for longer span restricted movement of the affected joints with severe swelling.

At Deep Ayurveda, we have the Following Herbal Oils and Capsules for treating Osteoarthritis.
a. Arthro-Joint Pain Oil.
b. Arthro-Joint Pain Capsules.
c. Shallaki Anti-Inflammatory Capsules.

Other than these patent medicines there are some Classical medicines which are very beneficial for curing arthritis are Dashmool ghana, Triphala Guggul, Maharasnadi quath, Maharasnadi quath granules, Vata Vidhwans Rasa, etc. These can be taken under the guidance of an Ayurvedic physician.

\section{Opinion}

Volume 7 Issue 6 - 2017

Baldeep Kour*

Rajiv Gandhi University of Health Sciences, India

*Corresponding author: Baldeep Kour, Co-Founder \& Medical Director of DEEP AYURVEDA, Rajiv Gandhi University of Health Sciences, India,

Email: info@deepayurveda.com

Received: January 30, 2017 | Published: July 07, 2017

\section{Diet for Osteoarthritis}

Diet of a patient suffering from Osteoarthritis should be freshly cooked and served hot. Soups of lentils, pulses, and meat should be taken by adding ginger and black pepper. Ghee and Oils are necessary for diet as they provide the lubrication to the joints and help in the smooth functioning of joints. The patient should avoid fried, sour and pungent foods as these cause damage to the degenerated joints.

\section{Exercise for Osteoarthritis}

The patient suffering from Osteoarthritis should do regular moderate exercise so that joint function properly and the problem does not carry further. 